\title{
Patients' Profile Regarding Physiatric Management of Facial Palsy in a Tertiary Care Hospital
}

\author{
PK CHAKRABORTY ${ }^{\mathrm{a}}$, MJ ISLAM ${ }^{\mathrm{b}}$, MS HOSSAIN ${ }^{\mathrm{c}}$, MN HASAN $^{\mathrm{d}}$ \\ MMNH KHANDKER $^{\mathrm{e}}$, ASMM UDDIN ${ }^{\mathrm{f}}$,
}

\begin{abstract}
Summary:
Introduction: Facial palsy is commonly treated by various physical therapy strategies and devices, but there are many questions about the profile of patients with facial nerve palsy. The aim of the study was to outline profile of patients with facial palsy receiving Physiatric management.

Materials and Methods: A retrospective hospital recordsbased study was carried out at the department of Physical Medicine and Rehabilitation (PMR) in National Institute of Neurosciences and Hospital (NINS\&H), Dhaka for the period of two year from 1st July 2013 to 30th June 2015.
\end{abstract}

Results: Total 5240 patients were studied, of which $58.87 \%$ were male and $41.13 \%$ were female. Maximum patients

Introduction:

The face plays a major role during interpersonal communication, and facial expression is of interest from both an evolutionary and a social standpoint. ${ }^{1}$ Facial

a. Dr. Prasanta Kumar Chakraborty, Assistant Professor, Department of Physical Medicine \& Rehabilitation, National Institute of Cancer Research and Hospital, Dhaka, Bangladesh

b. Dr. Md. Jahidul Islam, Associate Professor, Department of Physical Medicine and Rehabilitation, Dhaka Medical College, Dhaka, Bangladesh

c. Dr. Md. Shahadat Hossain, Vice Principal and Associate Professor, Department of Physical Medicine and Rehabilitation, Shaheed Suhrawardy Medical College, Dhaka, Bangladesh

d. Dr. Md. Nadimul Hasan, Associate Professor \& Head, Department of Dental \& Faciomaxillary Surgical Oncology, National Institute of Cancer Research \& Hospital, Mohakhali, Dhaka.

e. Dr. Md. Md. Nazmul Hasan Khandker, Assistant Professor, Department of Dental \& Faciomaxillary Surgical Oncology, National Institute of Cancer Research \& Hospital, Mohakhali, Dhaka.

f. Dr. A S M Minhaj Uddin, Registrar, Department of Physical Medicine and Rehabilitation, Shaheed Suhrawardy Medical College, Dhaka, Bangladesh

Address of Correspondence: Dr. Prasanta Kumar Chakraborty, Assistant Professor, Department of Physical Medicine \& Rehabilitation, National Institute of Cancer Research and Hospital, Dhaka, Bangladesh, Mobile: +8801718660967, E-mail: pkcborty@gmail.com Received: 2 August 2017 Accepted: 12 Dec. 2017
(26.58\%) belong to 31-40 years of age. Maximum patients (72.36\%) came from Dhaka city and most of the studied patients were housewife (31.68\%). Largest disease group was Bell's palsy (56.2\%). Regarding disease pattern, $61.18 \%$ of patients peripheral nervous system (PNS) and 38.82\% central nervous system (CNS) condition. Among etiologies of Facial palsy, 56.2\% Bell's palsy, 36.95\% stroke, 3.40\% Guillain-Barre' syndrome, 2\% traumatic, $0.52 \%$ were Ramsay-Hunt syndrome.

Conclusion: Profile of patients should be considered for Physiatric management of Facial nerve palsy.

Key wards: Facial nerve palsy, Patients'Profile.

(J Bangladesh Coll Phys Surg 2018; 36: 16-19)

nerve palsy causes weakness or paralysis of the facial muscles, accompanied by other complications. ${ }^{2}$ There are numerous causes of facial palsy (FP). Bell's palsy is a commonly encountered paralysis of the facial nerve occurring worldwide. ${ }^{3}$ In facial paralysis, alterations occur in the facial expression muscles depending on the level of the facial nerve lesion. In most cases, this is a spontaneously reversible phenomenon or is reversed after some type of treatment, either clinical or surgical. However, about $20 \%$ of patients develop some type of sequelae, which range from a light degree of paralysis to unilateral or bilateral complete paralysis of facial muscle movements. ${ }^{4}$

National Institute of Neuro-sciences (NINS) in Bangladesh was established with the vision of making this institute as the center of excellence not only in this country but also for others. It is a matter of pride that the institute has started functioning from September 2012. There are more than 15 departments. ${ }^{5}$ Physical Medicine and Rehabilitation is one of them. Almost all the patients came to this department were referred from different departments of NINS. Currently, lesions resulting in facial paralysis are difficult to treat and may cause facial expression alterations, with serious 
emotional consequences. To minimize sequelae, it is important to understand the causes and factors that could influence disease evolution.

\section{Objectives:}

\section{General:}

- To observe the profile of patients with facial nerve palsy attending the department of PMR in a tertiary care hospital. .

\section{Specific:}

- To identify demographic characteristics of patients with facial nerve palsy attending the department of PMR in a specialized hospital.

- To discuss the findings of this study with other available studies.

\section{Materials and Methods:}

We undertook a retrospective review of the records at Physical Medicine and Rehabilitation department of National Institute of Neuroscience and Hospital, Dhaka over a period of two year from 1st July 2013 to 30th June 2015 and determined the facial nerve palsy(FNP) diagnoses of attending patients. Information was extracted from the patients' records by means of a questionnaire assessing the participants' demographics and diagnoses. The subjects were enrolled on an individual basis, despite the varying number of visits by a given patient during the period of study.

Ethical approval: Permission was obtained from the concerned department and authority of the institute for compiling and publication of data records.

Statistical analysis and software used: Data were compiled into an Excel spreadsheet (Microsoft Corporation, Redmond, USA), which was used to tabulate demographic and etiological information. Simple proportions were used for categorized data.

Variables:

Primary variables:

o Disease profile

Secondary variables:

o Age

o Sex

o Catchment area

o Occupation

\section{Results:}

Between July 2013 and June 2015, 5240 patients (3085 men and 2155 women) received Physiatric management for FP of whom the demographic distribution of the frequencies were presented in Table-1.

Of the 5240 cases of FP, Table- 2 emphasizes the results related to the patients' profile. Patients received Physiatric management in the form of drugs, infrared therapy, electrical stimulation of facial muscles, ultrasound therapy, exercises of facial muscles, patient's instruction and counseling.

\section{Table-I}

Demographic characteristics of patients $(n=5240)$

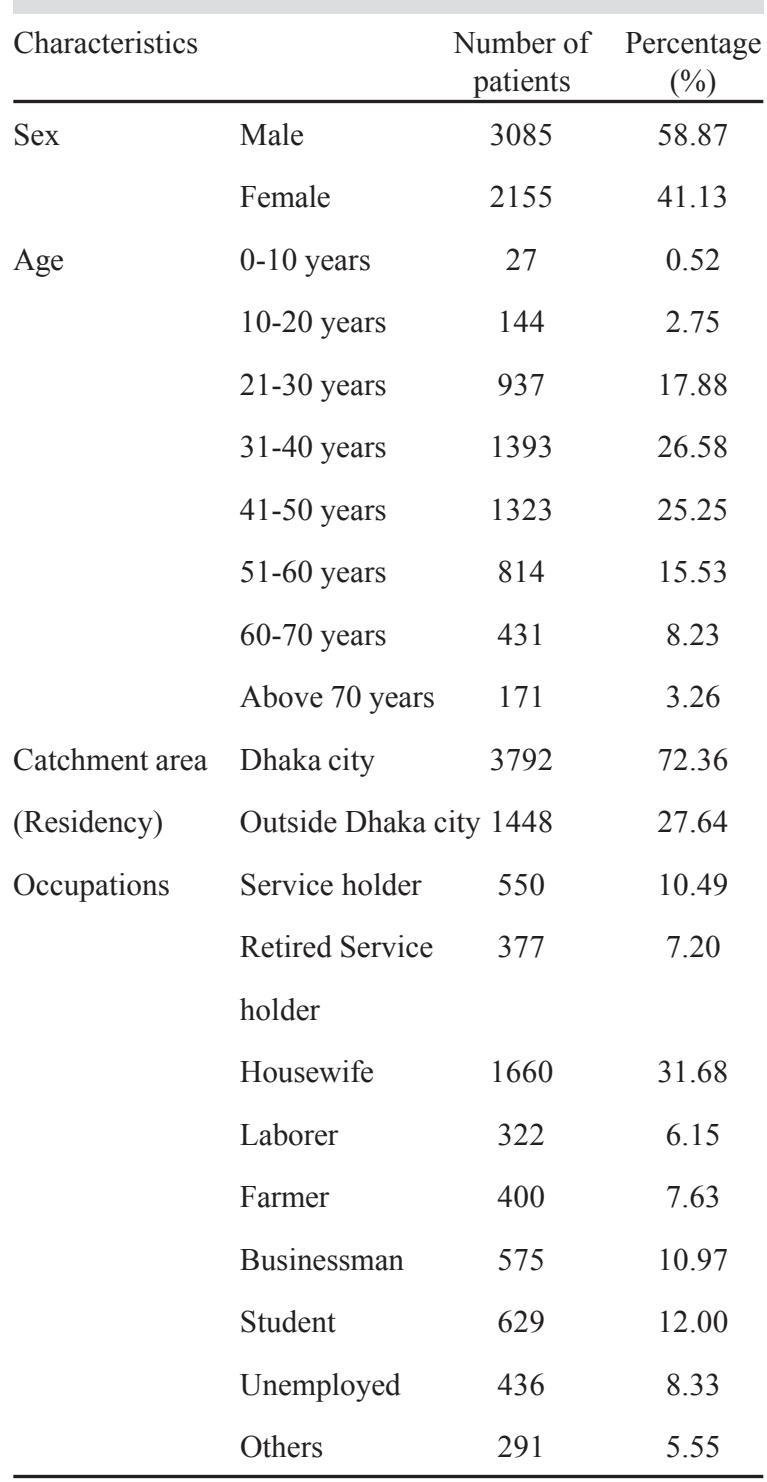


Table-II

\begin{tabular}{llcc} 
& Profile of Facial nerve palsy patients $(n=5240)$ & \\
Characteristics & & Number of patients & Percentage $(\%)$ \\
\hline Nervous system involved & Peripheral nervous system(PNS) & 3206 & 61.18 \\
& Central nervous system(CNS) & 2034 & 38.82 \\
Facial palsy onset & First time & 4636 & 88.47 \\
& Recurrent & 604 & 11.53 \\
Side of face affected & Right side & 2861 & 54.60 \\
& Left side & 2267 & 43.26 \\
Etiology/Factors associated & Both side & 112 & 2.14 \\
with Facial palsy & Idiopathic(Bell's palsy) & 2945 & 56.20 \\
& & & 36.95 \\
& Stroke & 1936 & 3.40 \\
& Guillain-Barre' syndrome & 178 & 2.00 \\
& Traumatic & 105 & 0.52 \\
& Ramsay-Hunt syndrome & 27 & 0.94 \\
\hline
\end{tabular}

\section{Discussion:}

A uniform data system (UDS) for Medical Rehabilitation is maintained in USA and published annually. No such system exists in Bangladesh. ${ }^{6}$ In this study it has been tried to find out the age, sex, occupation, residency and disease profile of patients with FP attending the department of PMR, NINS.

In this study, $58.87 \%$ were male and $41.13 \%$ were female. Junior NA et $\mathrm{al}^{7}$ showed that FP were predominant in males $(55.5 \%)$. Batista $\mathrm{KT}^{8}$ studied in a rehabilitation hospital that most of the patients were male patients. But, Hohman $\mathrm{MH}$ et $\mathrm{al}^{9}$ found $61 \%$ percent of patients were female. Lamina $S$ et $\mathrm{al}^{10}$ found that males $(56.2 \%)$ were higher incidence of FP than females(43.8\%). Stanley $\mathrm{M}$ et al ${ }^{11}$ showed male patients were more in number $(64.6 \%)$ than the females.

In present study, occupations of patients were housewife (31.68\%), labourer (6.15\%), serviceman (17.69\%), farmer $(7.63 \%)$, businessman $(10.97 \%)$ and student (12\%). Lamina S et $\mathrm{al}^{10}$ showed the incidence of FP which was highest among business men (31.6\%) followed by housewives (22.6\%) and least among medical personnel $(0.3 \%)$. Stanley $\mathrm{M}$ et $\mathrm{al}^{11}$ showed in occupational group, case notes of civil servants were in preponderance $(27.1 \%)$ and others were housewife $(20.8 \%)$, driver $(4.2 \%)$, farmer $(2.1 \%)$, trader $(18.8 \%)$, student $(20.8 \%)$, none $(6.2 \%)$.
In our study, $0.52 \%$ of patients were under 10 years of age, $2.75 \%$ were $11-20$ years, $17.88 \%$ were $21-30$ years, $26.58 \%$ were $31-40$ years, $25.25 \%$ were $41-50$ years, $15.53 \%$ were $51-60$ years, $8.23 \%$ were $61-70$ years and $3.26 \%$ above 70 years of age. Batista $\mathrm{KT}^{8}$ showed the prevalence of facial paralysis was greater among patients younger than 20 years. Lamina $\mathrm{S}$ et al ${ }^{10}$ showed that the middle age subcategory (20-34yrs) had the highest incidence of FP (40.3\%), while the old-age category (65yrs and above) had the least $(3.7 \%)$ incidence. Stanley $\mathrm{M}$ et $\mathrm{al}^{11}$ showed the case notes of the patients in the age group of 23-32 years were in majority $(37.5 \%)$.

Our study showed $61.18 \%$ of patients were peripheral nervous system (PNS) and 38.82\% central nervous system (CNS) condition. Stanley $\mathrm{M}$ et $\mathrm{al}^{11}$ showed Lower motor neuron FNP (56.2\%) predominated over upper motor neuron type (43.8\%).

Side of face affected in our study were right side $54.6 \%$, left side $43.26 \%$ and both side $2.14 \%$. Junior NA et $\mathrm{al}^{7}$ showed right side (66.6\%) and left side (33.4\%). Lamina $\mathrm{S}$ et $\mathrm{al}^{10}$ showed that $52.2 \%$ had right side, $46.1 \%$ had left side and very few $1.7 \%$ had bilateral FP.

Among etiologies of FP in this study, 56.2\% were Bell's palsy, $36.95 \%$ stroke, $3.40 \%$ Guillain-Barre' syndrome, $2 \%$ traumatic and $0.52 \%$ were Ramsay-Hunt syndrome. Junior NA et al ${ }^{7}$ showed that Bell's palsy was the most 
frequent etiology (53.7\%), followed by traumatic (24\%), Ramsay Hunt syndrome (9.2\%), Cholesteatoma (5.5\%), malignant otitis media (3.7\%) and acute otits media (3.7\%). Batista $\mathrm{KT}^{8}$ observed that majority of patients( $42.8 \%$ ) had Bell's palsy, $16.8 \%$ of congenital paralysis, $6 \%$ deriving from traumatic brain injuries, $18.9 \%$ due to stroke, $3.2 \%$ due to facial trauma, $3.2 \%$ due to tumors, $2.4 \%$ due to vestibular schwannoma, and $6.7 \%$ due to other etiologies. Study performed by Hohman $\mathrm{MH}$ et $\mathrm{al}^{9}$ found Bell's palsy accounted for $38 \%$ of cases, acoustic neuroma $10 \%$, cancer $7 \%$, iatrogenic injuries $7 \%$, varicella zoster $7 \%$, benign lesions $5 \%$, congenital palsy $5 \%$, Lyme disease $4 \%$, and other causes $17 \%$. Lamina $\mathrm{S}$ et $\mathrm{al}^{10}$ showed that the commonest cause of FP was idiopathic accounting for $39.1 \%$, followed by stroke $(30.0 \%)$, Otitis media however recorded $12.8 \%$, Herpes zoster being a cause of facial palsy had an incidence of $1.3 \%$, and least was measles with $0.3 \%$. Stanley $M$ et al ${ }^{11}$ showed Bell's palsy was reported as the highest cause of FNP, while the least cause of FNP was Ramsey-Hunt syndrome, However, stroke was implicated as the second highest cause of FNP in their study.

From the above discussion, it is clearly demonstrated that the findings of the study performed in PMR department of NINSH is consistent with the findings of different available studies.

\section{Limitation of the study:}

This study was done in one tertiary level hospital of Bangladesh in a small population and it may not reflect the total scenario of FP patients getting treatment from PMR department.

\section{Conclusion:}

Multidisciplinary approach and referrals in the management of FNP is essential for effective resolution of this ailing condition. Clinicians treating this condition must possess an awareness of the wide variety of FP etiologies; codifying the decision-making process is likely to result in fewer missed diagnoses and better outcomes. Although the data presented in this series are informative, they do not quantify the overall incidence or etiologic breakdown of FP.

\section{Recommendation:}

- A large scale multi-centered study should be performed in the country.
- A uniform data system should be constructed for Medical rehabilitation in Bangladesh.

\section{Acknowledgement:}

We express deepest regards and a profound debt of heart full gratitude to Head of PMR department, Joint Director and Director of NINS, Dhaka. We would like to thank our fellow colleagues, medical technologist and finally our family members for their kind cooperation and assistance in carrying out the study.

\section{Reference:}

1. Chang YS, Choi JE, Kim SW, Baek SY, Cho YS. Prevalence and associated factors of facial palsy and lifestyle characteristics: data from the Korean National Health and Nutrition Examination Survey 2010-2012. BMJ Open 2016; 6.

2. Wolf SL, Huang H. Evaluation of Biofeedback in Physical Medicine and Rehabilitation. In: Delisa JA, editor. Physical Medicine and Rehabilitation-principle and practice. 5th ed. Philadelphia: Lippincott Williams \& Wilkins; 2005. p.1942.

3. EL-Bab MF, Makhdoom N, Al-Harbi KM, Baghdadi HH, Alam A. Facial nerve palsy incidence, clinical feature and prognosis in AL Madinah AL-Munawarah. J. Basic. Appl. Sci. Res. 2011; 1(11): 2131-2136.

4. Vlastou C. Facial paralysis. Microsurgery 2006; 26(4): 27887.

5. Mohammad QD. Establishment of National Institute of Neuroscience and Hospital, Bangladesh perspective [editorial]. J Natl Inst Neurosci Bangladesh 2015; 1(1):1.

6. Hossain MS, Chakraborty PK, Rahman S, Islam MJ, Amin MR, Saha RK, et al. Diseases pattern in the department of Physical Medicine \& Rehabilitation in a tertiary level hospital. Bangladesh Med J. 2014 Sep; 43(3):130-133.

7. Junior NA, Jorge Junior JJ, Gignon VF, Kitice AT, de Almeida Prado LS, Wolff Santos VG. Facial Nerve Palsy: Incidence of different ethiologies in a tertiary ambulatory. Intl. Arch. Otorhinolaryngol., São Paulo 2009; 13(2):167-171.

8. Batista KT. Facial paralysis: epidemiological analysis in a rehabilitation hospital. Rev. Bras. Cir. Plást. 2011; 26(4): 591-5.

9. Hohman MH, Hadlock TA. Etiology, diagnosis, and management of Facial palsy: 2000 patients at a facial nerve center. Laryngoscope 2014, 124: 283-293.

10. Lamina S, Hanif S. Pattern of facial palsy in a typical Nigerian specialist hospital. African Health Sciences 2012; (4): $514-517$

11. Stanley M, Ifeanyi UC, Zuwera S, Yunus OA, Theophilus D, Abiodun JO. Review of facial nerve palsy at a tertiary hospital in Maiduguri, Nigeria. American Journal of Health Research 2016; 4(4): 100-103. 